\title{
Loaded and Unloaded Sit-to-Stand Strengthening Exercises Effect to Gross Motor Function Measure in Spastic Diplegia Cerebral Palsy Patients
}

\author{
Imran Safei, Marina A. Moeliono, Tertianto Prabowo \\ Department of Physical Medicine and Rehabilitation, Faculty of Medicine, Universitas Padjadjaran-Dr. Hasan \\ Sadikin General Hospital \\ Department of Physical Medicine and Rehabilitation, West Sulawesi, Indonesia
}

\begin{abstract}
Objective: To examine sit-to-stand and loaded sit-to-stand exercises effect in standing, walking, and running dimensions of gross motor function measure (GMFM) in spastic diplegia cerebral palsy (SDCP) patients.

Methods: This study was conducted in the period of May to October 2014 and included 24 children with SDCP as the subjects. The methods used in the study were interventional study with randomized controlled trial, and investigation of CP before and after the exercise intervention. The subjects were divided into two groups, sit-to-stand exercise group and loaded sit-to-stand exercise group.

Results: The results showed that the increase of standing, walking, and running dimension scores of GMFM in the loaded group were higher (standing dimension score 12.00 vs 11.08 and walking and running dimensions 13.58 vs 13.42) compared to the unloaded group.

Conclusions: Both sit-to-stand and loaded sit-to-stand exercise groups do not show significant differences in improving motor skills in standing, walking,

Received:

August 25, 2015 and running dimensions of GMFM. Children with SDCP may receive the exercise to improve their motor skills in mobility aspects, such as standing, walking, and running.
\end{abstract}

Revised:

December 29, 2015

Accepted:

February 26, 2016

Keywords: Cerebral palsy, gross motor function measure, rehabilitation, sit-to-stand exercise

IJIHS. 2016;4(1):8-14

\section{Introduction}

Cerebral palsy (CP) may cause chronic physical disabilities, especially in children. There are many CP cases that become a serious problem in the world, including a physical disability. Cerebral palsy is an abnormal movement and posture conditions commonly found in both infants and children. ${ }^{1,2}$ This condition may be caused by a nonprogressive brain disorder previous to, during pregnancy or immediately after delivery. Cerebral palsy is not categorized as a disease but the name is given to a static neuromotor disorder occurring during the developmental brain disorders (DBD). ${ }^{3}$

\footnotetext{
Correspondence:

Imran Safei, Department of Physical Medicine and

Rehabilitation, Faculty of Medicine, Universitas

Padjadjaran-Dr. Hasan Sadikin General Hospital

Jl. Pasteur No. 38, Bandung, Indonesia

e-mail: imransafei@yahoo.com
}

Additionally, cerebral palsy in childhood causes functional disabilities leading to very complex disabilities. Improvement of the motor skills in children may be influenced by the abnormal movement and posture conditions because the nonprogressive lesion presence in either infant cerebrum or growing children. ${ }^{4,5}$ The disabilities may infect other parts of the brain which cause sensory disorders, including seeing, hearing, and speaking problems.

Cerebral palsy incidences occured 2-2.5 per 1000 birth rate, however, a study stated that the CP incidences were 1-5 per 1000 birth rate in many countries. ${ }^{3}$ Many efforts have been performed to improve perinatal and maternal services to prevent PS but the number of incidences is still high. Several risk factors causing cerebral palsy are the increased number of premature and lower weight newborns. ${ }^{3-5}$ 
In addition, the CP treatments could be classified into two types, clinical signs and functional abilities. ${ }^{6}$ Due to the CP treatments based on the clinical signs, CP symptoms are categorized into three types: spastic diplegia cerebral palsy (SDCP) (pyramidal), dyskinetic cerebral palsy (extrapyramidal), and mixed cerebral palsy.

Cerebral palsy can be classified into five levels based on the functional abilities of gross motor function classification system (GMFCS): level I, can walk indoors and outdoors but has limitations in gross motor function; level II, can walk indoors and outdoors without a walker or a crutch but has limitations in crowds; level III, walk with a walker or crutch and has limitations in walking indoors, outdoors, and in crowds; level IV, has limited body movements and uses a walker or a wheelchair when walking outdoors and in crowds; and level $\mathrm{V}$, cannot independently walk even using assisstive technology. ${ }^{7}$ By the higher level of GMFCS is meant the lower level of the patient's functional abilities. The GMFCS levels I-III determine to improve the functional abilities and to enable to walk with or without a walker.

On the other hand, the number of SDCP patients are higher when compared to patients of the other two types. A study reported that the number of SDCP patients were approximately $75 \%$ of the CP total cases. ${ }^{1}$ In order to continue other studies, this study analyzed the CP cases, especially SDCP level II cases in children.

The subjects in this study performed the range of motion (ROM) exercises to lenghten the muscles and to maintain joint flexibilities. There are distinctive exercises which provide benefits for SDCP patients, including the sitto-stand strengthening exercise (Fig.1). The sit-to-stand exercise is regarded as functional activites such as the daily routines usually performed by children to improve their motor skills. ${ }^{4,6}$ Additionally, the distinctive treatment to SDCP patients through the passive range of motion exercises did not show significant improvement when compared to the sit-tostand exercise. The loaded and unloaded sitto-stand exercises in SDCP patients improved motor skills and body movements.

\section{Methods}

The subjects of this study were 6-14 years children with SDCP. Most of the subjects were registered as students while some of them as therapy members at the Yayasan Pembinaan Anak Cacat/Foundations for Disabled and Disadvantaged Children, Schools for Physically Disabled Children, Inclusive Schools, and Forum Komunikasi Keluarga Anak dengan Kecacatan/Family of Disabled and Disadvantaged Children Forums in West Java, Indonesia.

The consecutive sampling method was used to measure the number of sample. In the study, 24 subjects were randomly recruited. The selected subjects were children with SDCP level II who were able to use functional abilities to walk without a walker however, could not walk outdoors or in crowds. Then, the subjects were divided into two groups using the random permuted block design, the sit-to-stand exercise group and the loaded sitto-stand exercise group in a 7-week exercise. ${ }^{6}$

Moreover, the sit-to-stand exercise require greater momentum in the knees and hips such as stepping on a ladder. The principle of the
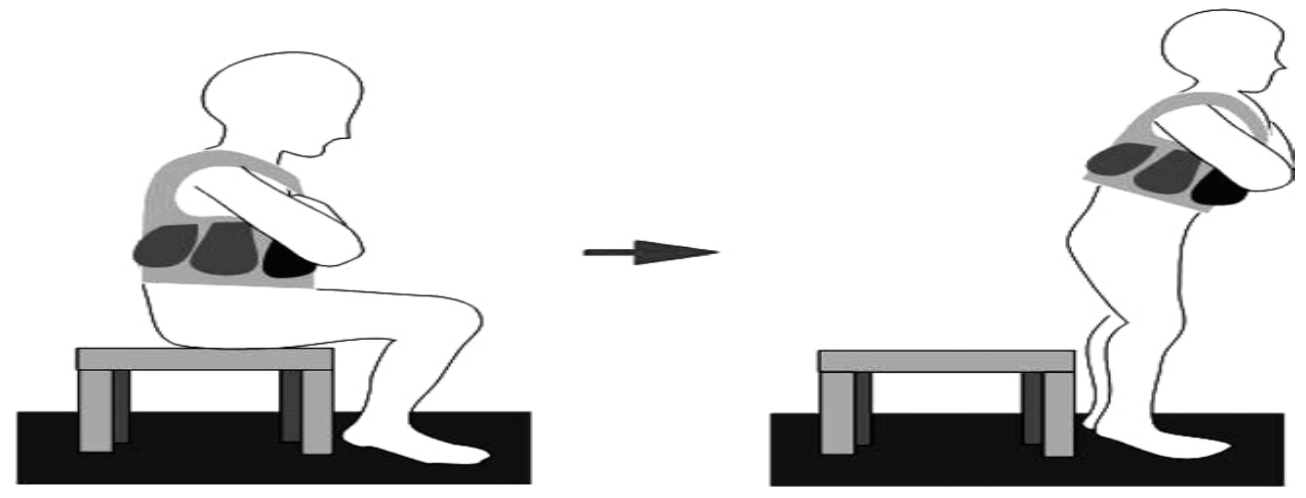

Fig. 1 Loaded Sit-to-Stand Exercise Conducted by a Child with Spastic Diplegia ${ }^{4}$ 
movements is to tranfer coordination from the stronger area of center of mass (COM) to the weaker area of base of support (BOS), however, the motor systems need fine balance. ${ }^{1,7}$

The methods used to analyze the data were the interventional study with randomized controlled trial, and investigation of CP before and after the exercise intervention. Then, the statistical normality test was performed first to analyze the data. Next, the numeric data were analyzed using the Shapiro-Wilk test to examine less than 50 samples. This study examined the subject physical characteristics, such as age, body mass index (BMD), height, weight, and head size. The subject's age, BMD, height, and weight were normaly distributed ( $>0.05)$ while the subject head size was not normaly distributed $(\mathrm{p}<0.05)$. Then, the distributed data were statistically calculated using the average and standard deviation. The undistributed data were statistically calculated using median.

This study was conducted to analyze the relationship between the loaded sit-to-stand exercise group and sit-to-stand exercise group in improving the motor skills in standing, walking, and running dimensions of GMFM in SDCP patients.

Both the subjects and parents signed the informed consent. This study was approved by the Health Research Ethic Committee, Faculty of Medicine, Universitas Padjadjaran.

\section{Results}

The subjects of this study were children with SDCP which were divided into two groups, the sit-to-stand exercise group and the loaded sitto-stand exercise group. This study compared the subject characteristics between the sit-tostand exercise group and loaded sit-to-stand

Table 1 Subject Characteristics

\begin{tabular}{|c|c|c|c|}
\hline \multirow[b]{2}{*}{ Characteristics } & \multicolumn{3}{|c|}{ Groups } \\
\hline & $\begin{array}{c}\text { Loaded Sit-to-Stand } \\
\text { Exercise } \\
(n=12)\end{array}$ & $\begin{array}{l}\text { Sit-to-Stand Exercise } \\
\qquad(\mathrm{n}=12)\end{array}$ & p Value \\
\hline Sex & & & $0.098^{*}$ \\
\hline Male & 5 & 9 & \\
\hline Female & 7 & 3 & \\
\hline Age (Yrs.) & & & $0.529 * *$ \\
\hline Average & $11.1(2.8)$ & $11.8(2.3)$ & \\
\hline Range & $7-14$ & $7-14$ & \\
\hline Weight (kg) & & & $0.786^{* *}$ \\
\hline Average & $29.2(9.2)$ & $30.2(8.6)$ & \\
\hline Range & $19-45$ & $18-45$ & \\
\hline Height (cm) & & & $0.839 * *$ \\
\hline Average & $128.6(15.1)$ & $129.9(16.6)$ & \\
\hline Range & $110-160$ & $107-160$ & \\
\hline Body Mass Index $\left(\mathrm{kg} / \mathrm{m}^{2}\right)$ & & & $0.662^{* *}$ \\
\hline Average & $17,2(2,6)$ & $17.6(2.1)$ & \\
\hline Range & $13.9-19.8$ & $14.9-21,4$ & \\
\hline Head Size $(\mathrm{cm})$ & & & $0.514^{* * *}$ \\
\hline Median & 50 & 49 & \\
\hline Range & $46-52$ & $45-52$ & \\
\hline
\end{tabular}


Imran Safei, Marina A. Moeliono, et al.

exercise group based on BMD, height, weight, and head size (Table 1 ).

The chi square test was performed to compare the patient's sex, while the t test was performed to compare the age, height, weight, and head size. The results showed that the subject characteristic comparison of both groups were not statistically significant $(p>0.05)$. Thus, the characteristic homogenity determined that the data were considered equal.

The subject's motor skills in standing dimension of GMFM before and after practicing the exercises were examined (Table 2). The statistical analysis showed the subjects had experienced improvements after practicing the exercises. The comparison of both groups were also examined to measure the different value.

Subsequently, the subject's improvement in standing dimension of GMFM before and after practicing exercises were compared. The comparison of both groups was considered statistically significant, since the loaded sit-tostand exercise group average value was 12.00 and standard deviation was 3.38. The sit-tostand exercise group average value was 11.08 and standard deviation was 1.24 .

The comparison of both groups revealed that the average value in standing dimension of GMFM after practicing the exercises showed significant improvements. The loaded sit-tostand exercise group improvement value was higher than the sit-to-stand exercise group. However, the higher value of the loaded sitto-stand exercise group was not considered statistically different ( $p>0.05$ ).

Then, the subject motor skill improvement in walking and running dimensions of GMFM before and after practicing exercises were compared (Table 3). The results showed significant motor skills improvements after performing the execises.

The examination of each group on walking and running dimensions of GMFM before and after performing the exercises was considered statistically significant. The loaded sit-tostand exercise group showed improvements with an average value 13.58 and a standard deviation 3.17 while the sit-to-stand exercise group average value was 13.42 and standard deviation was 1.67.

The comparison of both groups stated that the average value in walking and running

Table 2 Standing Dimension of Gross Motor Function Measure (GMFM) Comparison

\begin{tabular}{|c|c|c|c|}
\hline \multirow[b]{2}{*}{$\begin{array}{l}\text { Standing Dimension of GMFM } \\
\text { (Score) }\end{array}$} & \multicolumn{3}{|c|}{ Groups } \\
\hline & $\begin{array}{c}\text { Loaded Sit-to-Stand } \\
\text { Exercise } \\
(\mathrm{n}=12)\end{array}$ & $\begin{array}{l}\text { Sit-to-Stand Exercise } \\
\qquad(\mathrm{n}=12)\end{array}$ & p Value* \\
\hline Before performing exercise & & & 0.913 \\
\hline Average & $19.08(7.98)$ & $18.75(6.65)$ & \\
\hline Median & 21.00 & 20.50 & \\
\hline Range & $8-29$ & $8-27$ & \\
\hline After performing exercise & & & 0.612 \\
\hline Average & $31.08(5.35)$ & $29.83(6.49)$ & \\
\hline Median & 31 & 31 & \\
\hline Range & $22-38$ & $21-39$ & \\
\hline $\begin{array}{l}\text { Before and After Performing } \\
\text { Exercise Comparison** }\end{array}$ & $\mathrm{p}<0.001$ & $\mathrm{p}<0.001$ & \\
\hline $\begin{array}{l}\text { Standing Dimension } \\
\text { Improvements of GMFM }\end{array}$ & & & 0.388 \\
\hline Average & $12,00(3.38)$ & $11.08(1.24)$ & \\
\hline Median & 11.00 & 11.00 & \\
\hline Range & $8.00-19.00$ & $9.00-13.00$ & \\
\hline
\end{tabular}


dimensions of GMFM after practicing the exercises showed significant improvements. Additionally, the loaded sit-to-stand exercise group improvement value was also higher. However, the higher value of the loaded sitto-stand exercise group was not considered statistically different ( $p>0.05)$.

\section{Discussion}

Movement dysfunctions are caused by spastic diplegia cerebral palsy which may influence the body balance and the decrease of motor skills. Distinctive treatment to SDCP patients through passive range of motion exercises did not show significant improvement compared to the sit-to-stand exercise. The sit-to-stand exercise may improve the SDCP of the patient's motor skills and body movements. Therefore, the regular sit-to-stand exercise becomes the proper treatment to improve patient's body balance. The exercise can strenghten mucles and improve body balance and motor skills. ${ }^{8-10}$

The results in the study show no correlation in the SDCP subject characteristics on BMD, height, weight, and head size comparison. ${ }^{1,2}$

Children with SDCP may walk without a walker however, their motor skills worked slower than normal children. ${ }^{11}$ The children with SDCP functional abilities are classidied based on GMFCS. ${ }^{4,5}$

The subjects included in this study were children with SDCP type II who had functional abilities to walk without a walker. ${ }^{6}$ However, the subjects in this study had several limitations, such as walking outdoor or in crowds.

Additionally, walking ability in children will be completed when seven years old because it relates to the physiology process of feet growth. ${ }^{1,5,8}$ The distinctive exercises should be given to children aged 7-8years because at that period the body balance and posture control will be completed such as in adults. It means that children still have cooperative system in the body. Gross motor function classification system is useful to measure children abilities and self-esteem in the society which has categories: less than 2 year, 2-4 year, 4-6 year, and 6-12 year groups. ${ }^{5}$ However, the standard school age for disabled and disadvantaged children is 6-14 years. ${ }^{3,6}$

Table 3 Walking and Running Dimensions of Gross Motor Function Measure (GMFM) Comparison

\begin{tabular}{|c|c|c|c|}
\hline \multirow[b]{2}{*}{$\begin{array}{l}\text { Walking and Running } \\
\text { Dimensions of GMFM (Score) }\end{array}$} & \multicolumn{3}{|c|}{ Groups } \\
\hline & $\begin{array}{l}\text { Loaded Sit-to-Stand } \\
\text { Exercise } \\
(n=12)\end{array}$ & $\begin{array}{l}\text { Sit-to-Stand Exercise } \\
\qquad(n=12)\end{array}$ & p Value* \\
\hline Before performing exercise & & & 0.730 \\
\hline Average & $21.50(9.06)$ & $22,58(5,76)$ & \\
\hline Median & 22.50 & 23,50 & \\
\hline Range & $8-35$ & $10-32$ & \\
\hline After performing exercise & & & 0.714 \\
\hline Average & $35.08(6.75)$ & $36,00(5,26)$ & \\
\hline Median & 35.50 & 36,50 & \\
\hline Range & $25-44$ & $25-45$ & \\
\hline $\begin{array}{l}\text { Before and After Performing } \\
\text { Exercise Comparison** }\end{array}$ & $\mathrm{p}<0.001$ & $\mathrm{p}<0.001$ & \\
\hline $\begin{array}{l}\text { Walking and Running } \\
\text { Dimension Improvements } \\
\text { of GMFM }\end{array}$ & & & 0.874 \\
\hline Average & $13.58(3.17)$ & $13.42(1.67)$ & \\
\hline Median & 14.00 & 13.00 & \\
\hline Range & $9.00-21.00$ & $10.00-16.00$ & \\
\hline
\end{tabular}


Children with PSCP between 6-14 years old, with walking ability and self-esteem at the same level as in school, house, and society were involved in the study. Furthermore, the GMFM classification has been validated and are suitable for children between 5 months up to 16 years. ${ }^{5}$ Several studies also reported that loaded and unloaded sit-to-stand exercises increase the muscle strength, sensory motor integration, improving proprioception, body balance, and walking, running, and jumping dimensions of GMFM, and reduce energy expenditure. $2,8,12$

Gross motor skill in children with PSCP was measured using GMFM (Table 2). The loaded and unloaded sit-to-stand exercise groups' characteristic homogenity determined that the data were considered equal. After performing the exercises, the subjects showed significant improvements, including of the muscles. There are improvements in muscle strenght, such as flexor and extensor muscles of hips, knee, and Berg Balance Score. ${ }^{9,13,14}$

The improvements influence the children's gross motor skills. Additionally, the exercises improve the subject gross motor function in sitting, standing, running, as well as in other activities. Another study also reported that there are improvements in standing, walking, and running dimensions of GMFM after the subjects practicing the exercises. ${ }^{4}$

The sit-to-stand exercise can manage the lower parts of the body which are used to walk and enhance aerobic capacity and immune system that improves functional capacity. 4,5

The gross motor improvements in children can be measured by using the gross motor developmental milestones. The developmental milestones are markers of infant and child skill attainment occurring in a predictable sequence over time. Parents and clinicians use them to promote healthy development by identifying children who may be at risk for developmental problems as well as to provide opportunities for early intervention..$^{13}$ Standing, walking, and running are considered milestones which may be different among children. There should be a standard of age for children's improvement of gross motor due to maintain the children's daily activities.

The results showed that SDCP inhibited the subject gross motor function, including the abnormal range of motion and posture. There were malfunction and abnormal body structure on the nerves, muscles, joints, and bones. The primary disorder in the central nervous system (CNS) is followed by the loss of both inhibition and system connection to improve motor control activities. In the musculoskeletal, shortened muscles, inflexible joints, contractures, biomechanic changes, bone torque, and instability of joints are frequently found..$^{12}$ This condition inhibits the children's motor abilities and skills. The SDCP children mobilization and locomotion can be disrupted caused by muscle weakness and joint instability.

Thus, the subjects need greater energy to maintain body mass and to prevent inertia. A number of studies reported that loaded sitto-stand exercise may cause physiological adaptations, for instance neural adaptation, skeletal muscle adaptations, connective tissue adaptations, and metabolic adaptations. ${ }^{16,17}$

In this study, there are several limitations and needs improvements for further studies. The statistic results of the comparison between loaded sit-to-stand exercise and sit-to-stand exercise groups do not show significant value because of the small amount of the subjects. Therefore, the patients' weights in both groups were not appropriate that the results showed slight differences.

\section{References}

1. Misdalia T, Moeliono MA, Idjradinata $P$. Pengaruh Latihan Penguatan Duduk-Berdiri dengan Periodisasi terhadap Gross Motor Function Measure Dimensi D dan E Cerebral Palsy Spastik Diplegi. J Indon Med Assoc. 2012:62(10):397-401.

2. Reilly SD, Donkelaar Pv, Saavedra S, and Woollacott MH. The interaction between executive attention and postural control in dual-task condition children with cerebral

palsy. Arch Phys Med Rehabil. 2008;40(2):90102.

3. Berker N, Yalcin S. The help guide to cerebral palsy. Washington: Merrill Corporation; 2005.

4. Liao H-F, Liu Y-C, Lin Y-T. Effectiveness of loaded sit-to-stand resistance exercise for children with mild spastic diplegia: a randomized clinical trial. Arch Phys Med Rehabil. 2007;88(1):2531.

5. Yeargin-Allsopp M, Van Naarden Braun K, 
Doernberg NS. Prevalence of cerebral palsy in 8-year-old children in three areas of the United States in 2002: a multisite collaboration. Pediatrics. 2008;121(3):547-54.

6. Scholtes VA, Dallmeijer AJ, Rameckers EA, Verschuren 0, Tempelaars E, Hensen M, dkk. Lower limb strength training in children with cerebral palsy - a randomized controlled trial protocol for functional strength training based on progressive resistance exercise principles [Online Journal] 2008 [cited 20 Des 2014]. Available from: http://www.biomedcentral. com/1471-2431/8/41.

7. Palisano R, Rosembaum P, Walter S, Russel D, Wood E. Development and reliability of a system to classify gross motor functioning classification system for cerebral palsy. Dev Med Child Neurol. 1997;39(4):214-23.

8. Engsberg JR, Ross SA, Collins DR. Increasing ankle strength to improve gait and function in children with cerebral palsy: a pilot study. Pediatr Phys Ther. 2006;18:266-75.

9. Britton E, Harris N, Turton A. An exploratory randomized controlled trial of assisted practice for improving sit-to-stand in stroke patients in the hospital setting. Clinical Rehabilitation 2008;22(5):458-68.

10. Ross SA, Engsberg JR. Relationship between spasticity, strength, gait, and the GMFM-66 in person with spastic diplegia cerebral palsy. Arch Phys Med Rehabil. 2007;88(9):1114-20.

11. Prosser LA, Lee SCK, VanSant AF, Barbe MF,
Lauer RT. Trunk and hip muscle activation patterns are different during walking in young children with and without cerebral palsy. 2010; 90(7):986-97.

12. Graham HK. Mechanisms of deformity. In: Scrutton D, Mayston M, editors. Management of the motor disorders in children with cerebral palsy. London: Mac Keith Press; 2004.pp. 105129.

13. Tung FL, Yang YR, Lee CC, Wang RY. Balance outcomes after additional sit-to-stand training in subjects with stroke: a randomized controlled trial. Clin Rehabil. 2010;24(6):53342.

14. Rosie J, Taylor D. Sit-to-stand as home exercise for mobility-limited adults over 80 years of age-GrandStand System may keep you standing? Age Ageing. 2007;36(5):555-62.

15. Findlay L, Kohen D, Miller A. Developmental milestones among Aboriginal children in Canada. Paediatr Child Health. 2014;19(5):2416.

16. Sinaki M, Mokri B. Low Back Pain and Disorder of Lumbar Spine. In: Braddom RL, editor. Physical Medicine and Rehabilitation. Philadelphia: W.B.Saunders Company; 2000. p. 853-93.

17. Kisner C, Colby LA. Therapeutic ExerciseFoundations and Techniques. 2nd ed. Philadelphia: FA Davis Company; 1990. p. 65275. 